\title{
RELEVANCE OF ISOTHERM MODELS IN ADSORPTION OF Pb2+ BY AN BIOADSORBENT
}

\author{
Y.K. Meshram \\ Department of Chemistry, S.S.E.S. Amravati's Science College, Congress nagar Nagpur \\ (M.S.) India
}

\begin{abstract}
:
In the present work, batch adsorption experiments were carried out to investigate the suitability of prepared acid activated carbons in removing heavy metal ions such as lead (II). Activated carbons obtained from corn cobs and walnut shell (acrode) was activated using phosphoric acid. Synthesized activated carbons were modified. The results show that synthesized activated carbon can be used as an adsorbent for the removal of heavy metals. The adsorption equilibrium data for lead (II) from adsorption by activated carbons were analysed by Langmuir and Freundlich models.
\end{abstract}

Keywords: Adsorption, Heavy metals, Activated carbon, WSAC, CSAC, lead.

\section{INTRODUCTION:}

Global environmental pollution is a very serious problem. Contamination of heavy metals exists in water from several industries such as metal plating, mining, tanneries, paints, car radiator manufacturing, Battery industries as well as agricultural sources where fungicidal spray and fertilizers are rigorously used. The presence of organic, inorganic, biological or radiological factors which degrade the quality of water leads to water pollution. The heavy metal ions such as $\mathrm{Cu}, \mathrm{Fe}, \mathrm{Ni}$, $\mathrm{Pb}, \mathrm{Cd}, \mathrm{Mn}$ etc. in the environment is of major apprehension due to their toxicity. The heavy metals which is consumed by various life forms through food chains adversely affects the human being and environment (Buah, et al., 2016, Muthusamy, et al., 2016).

All Lead compounds are considered cumulative poisons. Lead poisioning affects gastrointestinal and nervous system, can damage almost all tissues, especially the immune system and kidneys. Lead exposure in high levels causes encephalopathy with the following symptoms: vertigo, insomnia, migraine, irritability, and even convulsions, seizures, and coma (Wuana, et al., 2011). The permissible limit for lead as per WHO is $0.01 \mathrm{mg} / 1$ (10 $\mu \mathrm{g} / 1$ ).Removal of heavy metals from contaminated water is a major concern from all point of view as metal ions are non-biodegradable in the nature and therefore their consumption at certain level are toxic. Several conventional methods are available for removal of heavy metal such as ion exchange, reverse osomosis, chemical precipitation, electrolysis (Dabrowski, et al., 2004, Charerntanyarak,1999). Most of the techniques are time consuming, costly, energy intensive. Thus adsorption method has been investigated as not only simple but also cost effective, efficient economical and easy availability. Low-cost bioadsorbents with high metal-binding capacity are increasingly being utilized for the removal of heavy metals. Inherent physico-chemical properties of bioadsorbents significantly influence their adsorption capacity. (Demirbas, et al., 2008, Ghasemi, et al., 2015, Ma M, et al., 2014, Tripathi A. 2015, SitiNur, 2013). Adsorbtion is the most emerging trend for the removal of heavy metals from waste water present work (Renge, et al., 2012). The aim of this work is to study equilibrium of adsorption of $\mathrm{Pb}$ (II) onto synthesized activated carbons.

\section{MATERIALS AND METHODS:}

All the solutions required for adsorption study were prepared in fresh and contaminant free distilled 
water. The distilled water necessary for the present work was obtained through a Double Distilled Water Plant. An Electric Oven Model (BIT, Bio-Techniques India, Mumbai-60.) having regulating system, was used for drying purpose. The desired value of temperature was maintained by using a regulator.

\section{Adsorbent preparation}

Corn cobs and Walnut shells were collected in large quantity in research laboratory from local Market, Nagpur. These were broken to smaller sizes and thoroughly washed with double distilled water to remove dirt and dried very well in an oven at $105^{\circ} \mathrm{C}$ for one hour. The corn cob samples as well as walnut shell was carbonized in the muffle furnace at optimum devolatization temperature of $300^{\circ} \mathrm{C}$ for 1hour. They were ground into powder and sieved through siever and particle ranging between 1400micron -1600 micron were kept for adsorption study. The chemical activation was carried out using $\mathrm{HNO}_{3}$. Aqueous solution of $\mathrm{HNO}_{3}$ reagents were prepared by adding $10 \mathrm{ml} \mathrm{HNO}_{3}$ in $100 \mathrm{ml}$ double distilled water. $50 \mathrm{~g}$ of the carbonized samples were weighed separately and mixed thoroughly with prepared solution of activating agent. They were heated for 15 minutes at the temperature of $350{ }^{\circ} \mathrm{C}$ and was washed with $0.5 \mathrm{M}$ acetic acid and rinsed with distilled water until their $\mathrm{pH}$ reached to neutral $\mathrm{pH} 7$ and then dried. The activated carbons thus obtained were finally smoothened, stored in well-fitted airtight corked bottles and properly labelled for further investigation. $0.5 \mathrm{gm}$ of the carbon sample which was kept in a weighing bottle in the same desiccator and its weight was monitored over a period of one week until it shows constant weight. The activated carbons thus obtained were finally smoothened, stored in well-fitted airtight corked bottles and properly labelled for further investigation (Olowoyo, et al., 2012).

\section{Preliminary treatment for SAC}

The selected SAC was first washed by hot distilled water several times until a clear visible liquid was obtained. Then distilled water was drained off and SAC was transferred to a petridish. Carbon was air dried properly to remove all the moisture on the surface of carbon and from pores of carbon. It was kept in an oven at temperature range 100-110 $\mathrm{C}$ for 6 hours and then cooled SAC was placed in desiccator containing $\mathrm{CaCO} 3$.

\section{Preparation of Metal ion solution}

The standard solution of lead nitrate (Loba make) was prepared by dissolving $1.656 \mathrm{gm}$ in distilled water and the solution was used for preparing solution of required concentration Lead solution was standardized with EDTA and lead were estimated. The $\mathrm{pH}$ of the solution was adjusted by adding $\mathrm{NaOH}$ or $\mathrm{H}_{2} \mathrm{SO}_{4}$. Distilled water used for the preparation of lead ion solution was obtained a fresh to avoid even slight traces of metal ions that could interfere in subsequent work.

For calibration curve, six systems containing different concentration of $\mathrm{Pb}^{2+}$ were prepared, $1 \mathrm{ml}$ $\mathrm{NaOH}(2 \mathrm{~N})$ and $2 \mathrm{ml}$ alizarin red solution were added in each system. These solutions were diluted to 50 $\mathrm{ml}$ and absorbance measured at $485 \mathrm{~nm}$ wavelength against a blank taken carefully in $1 \mathrm{~cm}$ path length matched glass cuvette using UV-Visible Spectrophotometer.

The absorbances of lead solution was measured by UV-visible spectrophotometer (chemito spectrascan UV-2700) at wavelength of $475 \mathrm{~nm}$.

\section{Batch adsorption experiment}

All the adsorption isotherms were carried out at a fixed temperature of $25^{\circ} \mathrm{C} \pm 1^{\circ} \mathrm{C}$ and as far as possible over at fixed intervals of time. For this, a water bath was used to maintain constant temperature of solution. $0.5 \mathrm{~g}$ weighed oxidized activated carbon of Corncob and Wallnut shell was transferred to the sets of five reagent bottles. $200 \mathrm{ml}$ of experimental lead solution pH 5.5 was carefully introduced in to the each reagent bottle. All the five 
reagent bottles and stirrer were kept in the water bath. The whole arrangement was stirred at a desired bath temperature for 5 hours.

After achieving the equilibrium, final concentration of solution was estimated spectrophotometrically. The absorbances of Lead solution were measured at $475 \mathrm{~nm}$ wavelength. Ten such systems of different concentrations were arranged. Calibration Curve using Beer's law is a general method for estimating the concentration of a metal in an unknown sample by comparing the unknown with standard samples of known concentration at constant temperature. In present study activated carbons synthesized from Corncob and Walnut shell are used for the removal of lead from synthetic wastewater.

\section{RESULT \& DISCUSSION :}

The equilibrium concentration of the lead on the activated carbons was obtained from the expression

$$
q_{e}=\left(C_{0}-C_{e}\right) \times \frac{V}{W}
$$

$\mathrm{q}_{\mathrm{e}}=$ Concentration of lead ion on GAC in $\mathrm{mg} / \mathrm{g}$,

$\mathrm{C}_{\mathrm{o}}=$ Initial concentration lead ion in solution in $\mathrm{mg} / \mathrm{L}$,

$\mathrm{C}_{\mathrm{e}}=$ Final concentration of lead ion in solution in $\mathrm{mg} / \mathrm{L}$,

$\mathrm{V}=$ Volume of solution in liters,

$\mathrm{W}=$ Weight of oxidised SAC in $\mathrm{g}(0.5 \mathrm{~g})$.

The equilibrium amount of lead adsorbed on SAC sharply increased initially and gradually settled to a maximum value with increase in concentration of lead.

Plots of $\mathrm{q}_{\mathrm{e}}$ versus $\mathrm{C}_{\mathrm{e}}$ then represented a typical adsorption isotherm for the lead ion on SAC. These adsorption isotherms are shown in Fig-1 and Fig-2. The data for adsorption isotherms of CSAC- HNO3$\mathrm{Pb}^{2+}$ and WSAC- HNO3- $\mathrm{Pb}^{2+}$ are given in the Table1. The adsorption data were applied to test for adherence of the adsorption of the lead ions to either the Langmuir or Freundlich adsorption isotherms.

The adsorption isotherm stated the relation between the amount of metal ion adsorbed per unit mass of SAC and the metal concentration in solution at equilibrium. The data obtained in adsorption equilibrium was tested by well-known isotherms i.e. Langmuir and Freundlich isotherms.

Langmuir isotherm model: The Langmuir model was proposed by Irving Langmuir. The Langmuir treatment is based on the assumption that maximum adsorption corresponds to a standard monolayer of adsorbate molecules on the adsorbent surface, that the energy of adsorption is constant and there is no transmigration of adsorbate in the plane of surface. Langmuir equation in terms qe and $\mathrm{C}_{\mathrm{e}}$ could be expressed as follows (Suresh Jeyakumar, et al., 2014).

$\mathrm{q}_{\mathrm{e}}=\frac{\mathrm{Q}^{\mathrm{O}} \mathrm{bC}_{\mathrm{e}}}{1+\mathrm{bC}_{\mathrm{e}}}$

Where,

$\mathrm{Q}^{\circ}=$ Amount adsorbed per unit weight of the adsorbent

$\mathrm{C}_{\mathrm{e}}=$ Equilibrium concentration of adsorbate solution in $\mathrm{mg} / \mathrm{L}$.

$\mathrm{q}_{\mathrm{e}}=$ Amount of adsorbate adsorbed per unit weight of adsorbent in $\mathrm{mg} / \mathrm{gm}$.

$\mathrm{b}=$ Langmuir constant.

Rearranging the above equation

$$
\frac{1}{\mathrm{q}_{\mathrm{e}}}=\frac{1}{\mathrm{Q}^{\mathrm{O} b}} \times \frac{1}{\mathrm{C}_{\mathrm{e}}}+\frac{1}{\mathrm{Q}^{\mathrm{O}}}
$$

Freundlich isotherm model-The Freundlich equation is the empirical relationship whereby it is assumed that the adsorption energy of binding to a site on an adsorbent depends on whether or not the adjacent sites are already occupied. One limitation of the Freundlich model is that the amount of adsorbed solute increases indefinitely with the concentration 
of solute in the solution. The Freundlich equation is represented as

$q_{e}=k \cdot C e^{\frac{1}{n}}$

Above equation may be linearised as

$\log q_{e}=\log k+\frac{1}{n} \log C e$

A plot of $\log \mathrm{q}_{\mathrm{e}}$ versus $\log \mathrm{C}_{\mathrm{e}}$ was fairly showing validity of Freundlich equation over a range of concentration

Fig. 3, Fig.4 and Fig.5,Fig.6 illustrate the plot of Langmuir and Freundlich isotherm for CSAC_Pb ${ }^{2+}$ and WSAC_Pb ${ }^{2+}$ respectively The plot of $1 / \mathrm{q}_{\mathrm{e}}$ versus $1 / \mathrm{C}_{\mathrm{e}}$ found to be linear indicating applicability of Langmuir model. The parameter $\mathrm{Q}^{\circ}$ and $\mathrm{b}$ are Langmuir constant relating to the adsorption capacity and adsorption energy respectively. The validity of the isotherm equation is judged by comparing the correlation coefficient $\mathrm{R}^{2}$. Langmuir model satisfactorily fits to the experimental data of lead. The intercept and slope of the linear plot of $\log \mathrm{q}_{\mathrm{e}}$ versus $\log \mathrm{C}_{\mathrm{e}}$ and $1 / \mathrm{qe}$ versus $1 / \mathrm{C}_{\mathrm{e}}$ under given set of experimental condition provide values of $\mathrm{k}_{\mathrm{f}}$, $1 / \mathrm{n}, \mathrm{Q}^{0}$ and $\mathrm{b}$ respectively. The corresponding Freundlich and Langmuir constant obtained are listed below in Table-1.

\section{CONCLUSION :}

From the above studies it is concluded that activated carbon synthesized from walnut shell and corncob are suitable and efficient material for the adsorption of lead from aqueous solution. From adsorption isotherm, it revealed that at low concentration, uptake of lead by SAC was fast, and at high concentration, it seemed to be constant. The oxidation with $\mathrm{HNO} 3$ creates large number of active sites on the surface of activated carbon for approaching metal ions. The experimental data showed satisfactory adsorption of metal ion and good fit to Langmuir isotherm model. The process was found to be cost effective and promising for the removal of toxic metals.

\section{ACKNOWLEDGEMENT:}

The author is very grateful to the Principal, SSES Amravati's Science, College, Congress nagar, Nagpur, for providing necessary laboratory facilities to carry out the experimental work.

\section{REFERANCES :}

Buah, W., MacCarthy, J. (2016). International Journal of Environmental Protection and Policy,Vol. 4, 98-103.

Muthusamy, P., Murugan, S. (2016).Removal of Lead Ion Using Maize Cob as a Bio adsorbent. Int. Journal of Engineering Research and Application Vol. 6, Issue 6, 0510 .

Wuana, R.A., and Okieimen, F. E., (2011). Heavy Metals in Contaminated Soils: A Review of Sources, Chemistry, Risks and Best Available Strategies for Remediation. International Scholarly Research Network; 1-20.

Dą̧rowski, A., Hubicki Z., Podkościelny, P., and Robens, E.(2004). Selective removal of the heavy metal ions from waters and industrial wastewaters by ion-exchange method. Chemosphere, vol. 56, (2), 91-106,

Charerntanyarak, L., (1999). Heavy metals removal by chemical coagulation and precipitation. Water Science and Technology, 39, no. 10$11,135-138$.

Renge, V. C., Khedkar, S. V., Pandey S., (2012).Removal of heavy metals from wastewater using low cost adsorbents: a review.Scientific Reviews and Chemical Communications, 2 (4), 580-584

Demirbas, E., Kobya, M., Konukman, AES. (2008). Error analysis of equilibrium studies for the almond shell activated carbon adsorption of 
$\mathrm{Cr}(\mathrm{VI})$ from aqueous solutions. Journal of Hazardous Materials, 154, 787-794.

Ghasemi, M., Ghoreyshi, A.A., Younesi H, Khoshhal, S. (2015). Synthesis of a high characteristics activated carbon from walnut shell for the removal of $\mathrm{Cr}$ (VI) and $\mathrm{Fe}$ (II) from aqueous solution: single and binary solutes adsorption. Iranian Journal of Chemical Engineering, Vol. 12; 4.

Ma, M.G., Wei, Y., Zhao, G., Liu F., Zhu, Y.R.(2014).Characterization and Adsorption Mechanism of $\mathrm{Pb}$ (II) Removal by Insolubilized Humic Acid in Polluted Water. International Journal of Environmental Protection and Policy, Vol. 2 (6) , 230-235.

Tripathi, A., Ranjan MR., (2015). Heavy Metal Removal from Wastewater Using Low Cost Adsorbents. J Bioremed Biodeg., 6; 315.
SitiNur, AA., MohdHalim, SI., Lias, KamalMd., Shamsul, I. (2013). Adsorption Process of Heavy Metals by Low-Cost Adsorbent: A Review. World Applied Sciences Journal, 28, 1518-1530.

Olowoyo, D. N., Garuba, A.O. (2012).Adsorption of Cadmium Ions using activated carbon prepared from Coconut shell, Global Advanced Research Journal of Food Science and Technology, 1(6) ,81-84.

Suresh Jeyakumar, R. P., \& Chandrasekaran, V. (2014). Adsorption of lead(II) ions by activated carbons prepared from marine green algae: Equilibrium and kinetics studies. International Journal of Industrial Chemistry, vol 5 (2), 2-10.

Table 1 Isotherm constants for the adsorption of $\mathrm{Pb}^{2+}$ on WSAC and CSAC

\begin{tabular}{|c|c|c|c|c|c|c|c|c|}
\hline Sr No & \multicolumn{2}{|c|}{ System } & \multicolumn{2}{c|}{ Langmuir constant } & \multicolumn{2}{c|}{ Freundlich constant } \\
\hline & & qemax & $\mathbf{Q}^{\circ}$ & b & $\mathbf{R}^{2}$ & $\mathbf{1} / \mathbf{n}$ & $\mathbf{k f}$ & $\mathbf{R}^{2}$ \\
\hline 1 & $\begin{array}{c}\text { System: CSAC- } \\
\mathrm{HNO3-Pb}\end{array}$ & 2.588 & 2.869 & 3.095 & 0.999 & 0.259 & 2.015 & 0.923 \\
\hline 2 & $\begin{array}{c}\text { System: WSAC- } \\
\text { HNO3- Pb }\end{array}$ & 2.421 & 2.572 & 4.502 & 0.978 & 0.193 & 1.990 & 0.904 \\
\hline
\end{tabular}




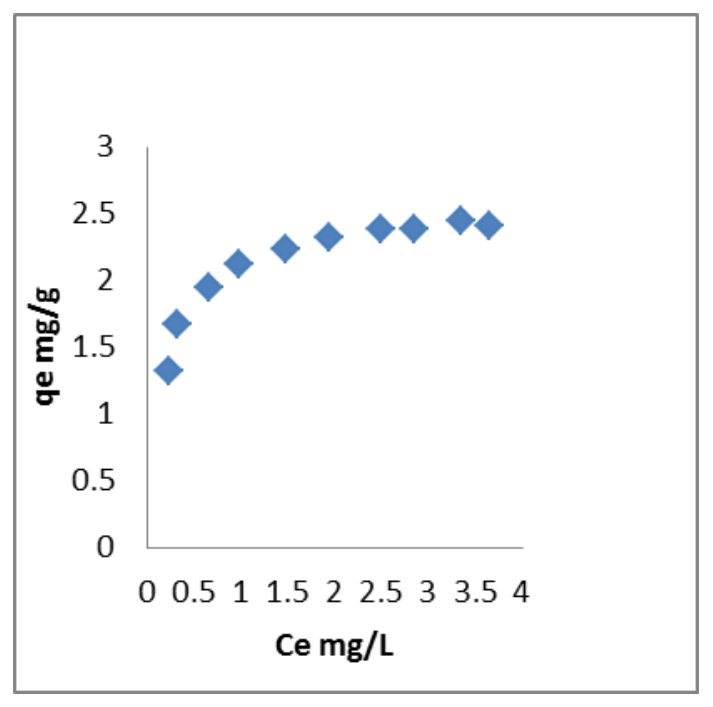

Fig. 1-Adsorption isotherm system: CSAC- $\mathrm{HNO} 3-\mathrm{Pb}^{2}$

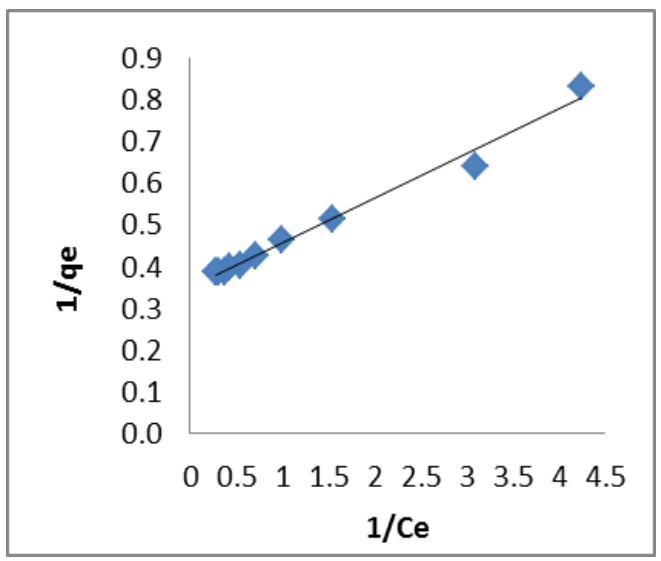

Fig. 3- Langmuir adsorption isotherm system: CSAC- $\mathrm{HNO} 3-\mathrm{Pb}^{2+}$

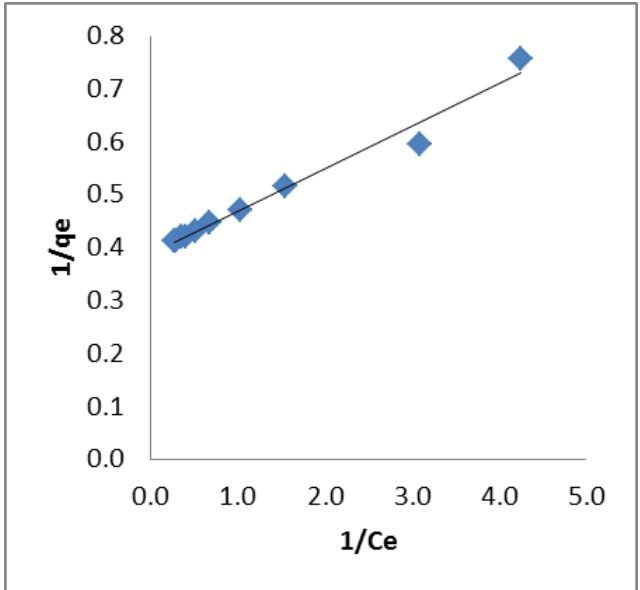

Fig. 5- Langmuir adsorption isotherm system: WSAC- $\mathrm{HNO} 3-\mathrm{Pb}^{2+}$

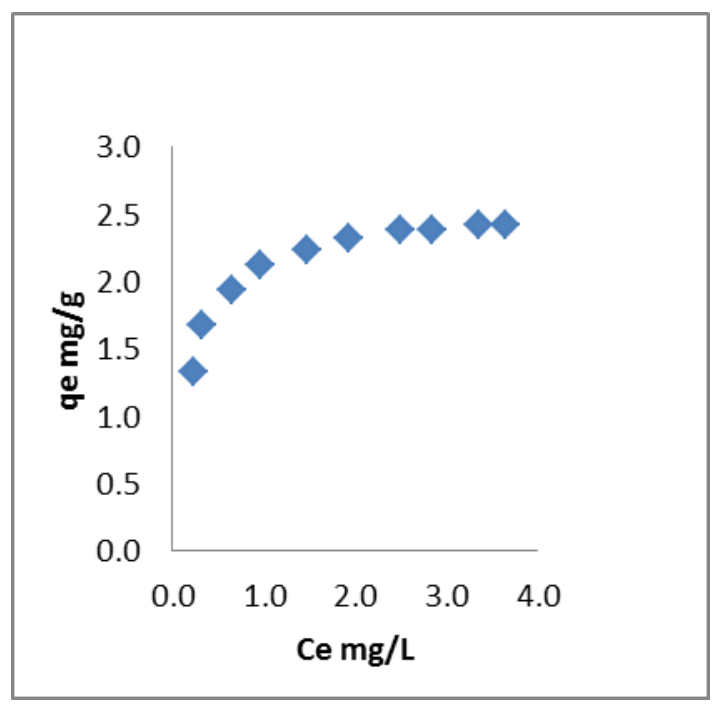

Fig. 2 -Adsorption isotherm system: WSAC- HNO3- $\mathrm{Pb}^{2}$

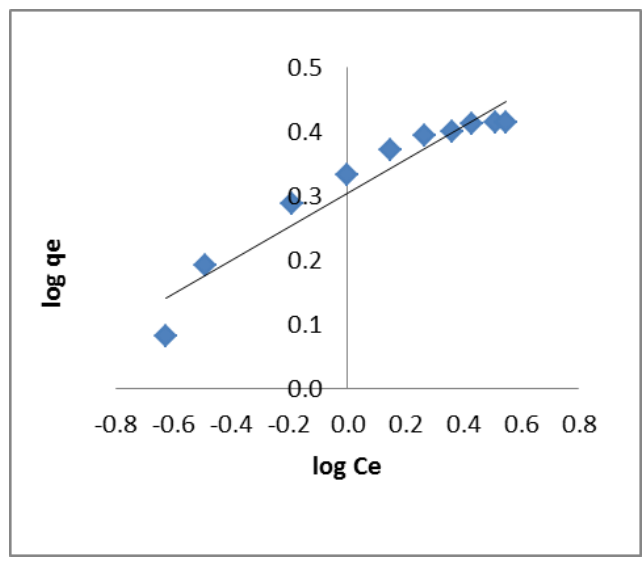

Fig.4 -Frendlich Adsorption isotherm system: CSAC- $\mathrm{HNO} 3-\mathrm{Pb}^{2+}$

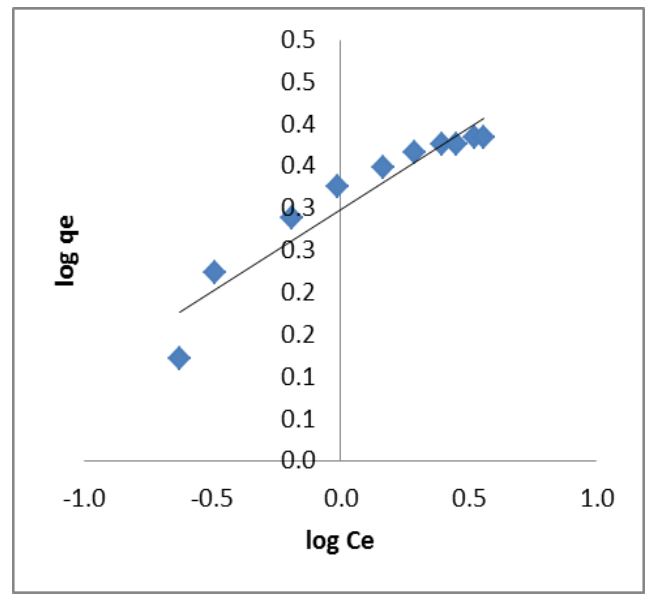

Fig. 6 -Freundlich Adsorption isotherm system: WSAC- HNO3- $\mathrm{Pb}^{2+}$ 